\title{
Research on the Sharing Bicycles Delivery
}

\author{
JianYuan Gan 1,a , Lin Zhang 1,b, XiaoQ ing Huang 1,c, RongFang Hu 1,d \\ ${ }^{1}$ School of Mathematics and Information Science, Nanchang Hangkong University, Nanchang \\ 330063, China

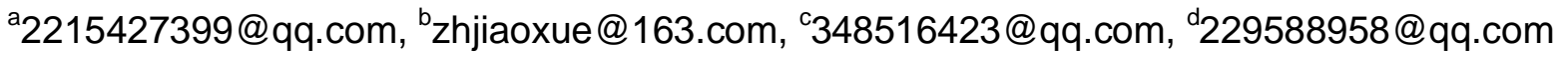

Keywords: urban transportation; sharing bicycles; delivery; Markov

Abstract: Sharing bicycles in the settlement of the user "last mile" short-distance travel needs and ease the urban traffic congestion plays an increasingly important role. In order to study the issue of sharing bicycles delivery, firstly, a bicycles' market demand model considering the age distribution is established, calculate the capacity of a city or region for sharing bicycles. Through the use of Markov chain, the establishment of a specific area of shared bicycles (residence, workplace, campus, park, business center and subway / bus station) model, analysis the relationship between demand and sharing bicycles delivery in the six regions, ensure the scientific and reasonable number of delivery.

\section{Introduction}

Sharing bicycles provides citizens with a great convenience in solving the "last mile" and quietly changes the way of theirs' life. Only two years have passed since the real development of shared bicycles. "Mobike and ofo basically have more than 20 million bills per day. Taobao has spent 10 years, and now it is only 30 to 40 million each day. The mass of Mobike and ofo is the same as that of Taobao." ofo investor Zhu Xiaohu said," The last point is very important. We must very quickly occupy the market on a large scale. Fastest is all in the Internet, and it needs to occupy the market quickly and massively." However, along with it, the scale of sharing bicycles exceeds the degree that urban public resources can accommodate, and the illegality of road occupation is getting more and more serious, especially in places with high traffic, such as near commercial centers and subways. Many bicycles are parked at will, not only affecting the city appearance, but even affecting traffic safety. In fact, the sharing bicycles park at random is not entirely the reason for the quality of citizens. At present, the amount of sharing bicycles is far more than parking resources. Many times, sharing bicycles do not allow parking in non-motorized parking spaces, and citizens can only choose to park in violation of regulations.

Many city governments now talk about sharing bicycles companies stop delivering sharing bicycles. If the government does not talk about it, is it still necessary to continue to deliver sharing bicycles, and if it continues to do, will urban public resources provide enough support? So the amount of sharing bicycles delivery is the direction that we need to grasp. How to accurately measure the city's capacity for sharing bicycles and how to ensure a scientific and reasonable number of bicycles delivery? These are two difficult problems. ${ }^{[1]}$ This article aims at these two issues and establishes a bicycle market demand model that takes age distribution into account to calculate the delivery. Analyze the relationship between the amount of supply of shared bicycles and the demand in a specific area (home, work place, campus, park, commercial center, and subway/bus station) with high personal traffic in the city 6 via the Markov chain. 


\section{Sharing bicycles market demand model considering age distribution}

Considering some factors related to the growth of sharing bicycles market demand, two obvious factors are user growth rate and user loss rate, and the two rates are determined by different factors. The user growth rate is affected by economy, environment, age distribution, income status, education level, lifestyle, bicycle advertisements, etc; and the user loss rate is affected by factors such as the convenience of getting the bicycle and the cost performance of the bicycle. In the forecast of market demand, the users' age distribution is very important, because the proportion of young people in different cities or regions is different, then the demand of users will be different. According to the survey, young people aged 20 to 39 are the main users of bicycles. Users under the age of 19 are more concentrated in universities and high schools, while users over the age of 20 are scattered throughout universities, office workers, and urban workers. ${ }^{[2]}$

In our model, we only consider user growth rate and user loss rate, ignoring other factors (If we are not satisfied with the results, we can also be more precise, and can add these factors to the simulation model.) The number of users has been increasing since the early user loss rate is far less than the user growth rate.

To study the number of different ages' users at any time, introduce the user's distribution function and density function. A user whose age less than $x$ at time $t$ is called user distribution function, and it is denoted as $F(x, t), t \geq 0, x \geq 12$ (person under 12 are prohibited from sharing bikes) and $t, x$ are continuous variables. Let $F(x, t)$ be continuous and differentiable. The total number of users at time $t$ is recorded as $N(t)$, the highest age is recorded as $x_{m}$, and suppose $x_{m} \rightarrow \infty$. when doing theoretical derivation. So for non-negative and non-drop function $F(x, t)$, there is

$$
F(12, t)=0, \quad F\left(x_{m}, t\right)=N(t) .
$$

The user density function is

$$
p(x, t)=\frac{\partial F}{\partial x}
$$

$p(x, t) d x$ indicates the number of users at time $t$ within the age range $[x, x+d x)$.

Let $\mu(x, t)$ is the user loss rate whose age is $x$ at time $t . \mu(x, t) p(x, t) d x$ indicates the number of users lost per unit of time at time $t$ within the age range $[x, x+d x)$.

In order to get $p(x, t)$ satisfied equation, examine the case of the user whose age is within the age range $[x, x+d x)$ at time $t$ to $t+d t$. The age of users who are still using bicycles has changed $\left[x+d x_{1}, x+d x+d x_{1}\right)$, here is $d x_{1}=d t$. The number of users lost during this period $d t$ is $\mu(x, t) p(x, t) d x d t$. So

$$
p(x, t) d x-p\left(x+d x_{1}, t+d t\right) d x=\mu(x, t) p(x, t) d x d t .
$$

Notice that $d x_{1}=d t$, we can get

$$
\frac{\partial p}{\partial x}+\frac{\partial p}{\partial t}=-\mu(x, t) p(x, t) \text {. }
$$

Here, the loss rate $\mu(x, t)$ is a known function.

Equation (4) has two definite solution conditions: the initial density function is noted as $p(x, 0)=p_{0}(x)$; User's growth number in unit time is noted as user growth rate $p(12, t)=f(t)$, Write equation (4) and definite solution conditions as 


$$
\left\{\begin{array}{l}
\frac{\partial p}{\partial x}+\frac{\partial p}{\partial t}=-\mu(x, t) p(x, t), \quad t>0, x>12, \\
p(x, 0)=p_{0}(x) \\
p(12, t)=f(t) .
\end{array}\right.
$$

The solution process of equation (5) is more complicated, we only consider that in the situation of market stability and not too long, the loss rate is roughly independent of time, then approximate assumption $\mu(x, t)=\mu(x)$. At this time, the solution of equation (5) is

$$
p(x, t)= \begin{cases}p_{0}(x-t) e^{-\int_{x-t}^{x} \mu(s) d s}, & 0 \leq t \leq x, \\ f(t-x) e^{-\int_{0}^{x} \mu(s) d s}, & t>x .\end{cases}
$$

Due to age, users aged 12 to 50 years are selected as the sharing bicycles users. Then the total number of users is

$$
N(t)=\int_{12}^{50} p(x, t) d x= \begin{cases}\int_{12}^{50} p_{0}(x-t) e^{-\int_{x-t}^{x} \mu(s) d s} d x, & 0 \leq t \leq x, \\ \int_{12}^{50} f(t-x) e^{-\int_{0}^{x} \mu(s) d s} d x, & t>x .\end{cases}
$$

The profitability of a sharing bicycle lies in its daily turnover rate $\alpha$, which is defined as the reciprocal of the number $c$ times that a bicycle is used per day.

$$
\alpha=\frac{1}{c} \text {. }
$$

So, the maximum number of bicycles that can be deliver in a city or area is

$$
N_{m}=\alpha N(t) \text {. }
$$

In addition, we can also define other indices, such as the average use time $S(t)$ : no matter how long the user at time $t$ uses the bicycle, the loss rate is calculated according to $\mu(x, t)$.

$$
S(t)=\int_{t}^{\infty} e^{-\int_{0}^{\delta-t} \mu(x, t) d x} d \delta
$$

\section{Sharing bicycle specific area model}

According to the user's travel habit survey, the data of sharing bicycle users is obtained ${ }^{[3,4]}$ :

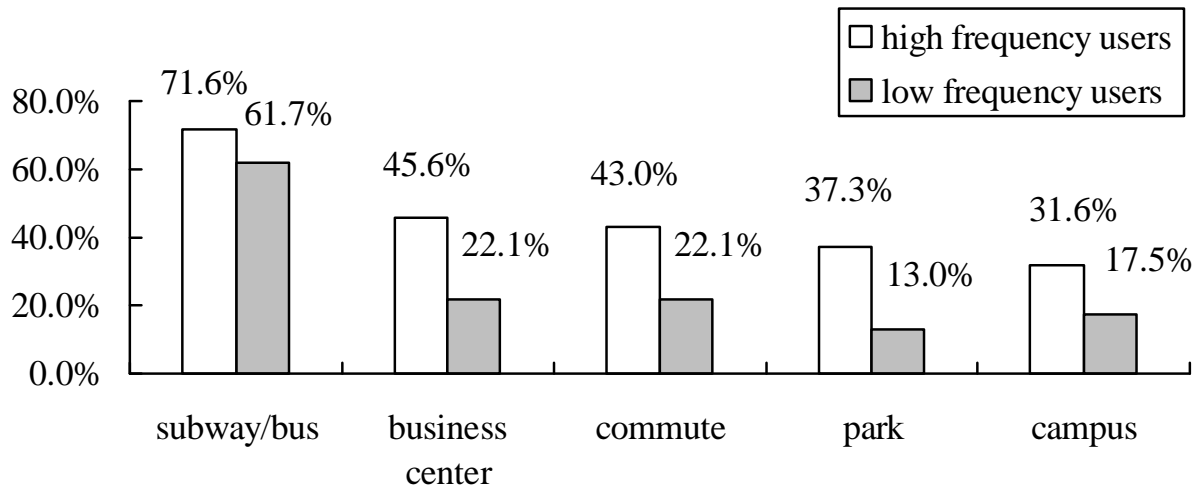

Fig. 1 Sharing bicycle user usage scenario in January 2017

According to Fig. 1, we select 6 specific areas (residence, workplace, campus, park, commercial 
center, subway/bus station) with high flow of people in a city as object of study. Collect sharing bicycles data in these 6 specific areas and these data are shown in Table 1 and Fig. 2 below:

\section{Table 1 Specific Area Transfer Matrix}

\begin{tabular}{|c|c|c|c|c|c|c|c|}
\hline & & \multicolumn{6}{|c|}{ next state } \\
\hline & & residence & workplace & campus & park & $\begin{array}{c}\text { commercial } \\
\text { center }\end{array}$ & $\begin{array}{c}\text { subway/bus } \\
\text { station }\end{array}$ \\
\hline \multirow{6}{*}{$\begin{array}{l}\text { previous } \\
\text { state }\end{array}$} & residence & 0.05 & 0.18 & 0.13 & 0.15 & 0.19 & 0.30 \\
\hline & workplace & 0.20 & 0.03 & 0.01 & 0.07 & 0.18 & 0.51 \\
\hline & campus & 0.10 & 0.02 & 0.28 & 0.09 & 0.19 & 0.32 \\
\hline & park & 0.19 & 0.06 & 0.13 & 0.11 & 0.21 & 0.30 \\
\hline & $\begin{array}{c}\text { commercial } \\
\text { center }\end{array}$ & 0.22 & 0.10 & 0.20 & 0.09 & 0.08 & 0.31 \\
\hline & $\begin{array}{c}\text { subway/bus } \\
\text { station }\end{array}$ & 0.19 & 0.28 & 0.18 & 0.15 & 0.17 & 0.03 \\
\hline
\end{tabular}

These data are called transfer matrices. It shows that the probability of returning bicycles rented at the residence to residence, work place, campus, park, commercial center, subway/bus station is $0.05,0.18,0.13,0.15,0.19,0.30$; the other is similar. This gives a Markov process with six states, namely residence, work place, campus, park, business center and subway/bus station. This process is shown in Fig. 2.

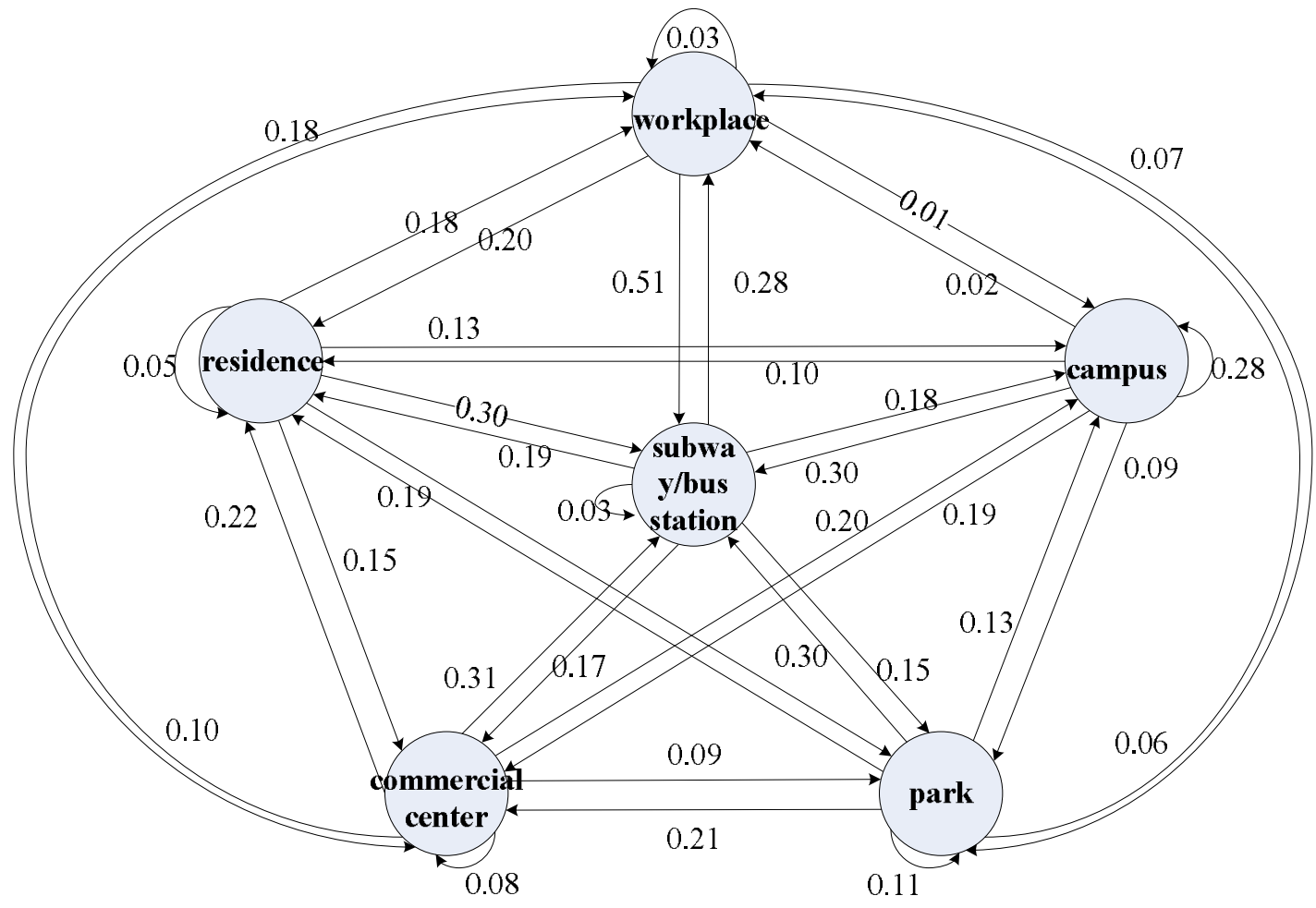

Fig. 2 6-state Markov Chains in Specific Areas

So, according to the Markov chain, define the following variables:

$J_{n}=$ percentage of bicycles available for rent at the residence at the end of the nth period,

$G_{n}=$ percentage of bicycles available for rent at workplace at the end of the nth period,

$X_{n}=$ percentage of bicycles available for rent at campus at the end of the nth period,

$Y_{n}=$ percentage of bicycles available for rent at park at the end of the nth period,

$S_{n}=$ percentage of bicycles available for rent at commercial center at the end of the nth period, 
$D_{n}=$ percentage of bicycles available for rent at subway/bus station at the end of the nth period. Using the above data, the following equations are constructed:

$$
\left\{\begin{array}{l}
J_{n+1}=0.05 J_{n}+0.18 G_{n}+0.13 X_{n}+0.15 Y_{n}+0.19 S_{n}+0.30 D_{n}, \\
G_{n+1}=0.20 J_{n}+0.03 G_{n}+0.01 X_{n}+0.07 Y_{n}+0.18 S_{n}+0.51 D_{n}, \\
X_{n+1}=0.10 J_{n}+0.02 G_{n}+0.28 X_{n}+0.09 Y_{n}+0.19 S_{n}+0.32 D_{n}, \\
Y_{n+1}=0.19 J_{n}+0.06 G_{n}+0.13 X_{n}+0.11 Y_{n}+0.21 S_{n}+0.30 D_{n}, \\
S_{n+1}=0.22 J_{n}+0.10 G_{n}+0.20 X_{n}+0.09 Y_{n}+0.08 S_{n}+0.31 D_{n}, \\
D_{n+1}=0.19 J_{n}+0.28 G_{n}+0.18 X_{n}+0.15 Y_{n}+0.17 S_{n}+0.03 D_{n} .
\end{array}\right.
$$

Assume that the number of deliver bicycles in residence, work place, campus, park, business center, subway/bus station is equal, i.e. each is $1 / 6$. The numerical solution of equation (11) gives the long-term trend of the percentage of bicycles in each specific area. The sum of these percentages or probabilities is equal to 1. Table 2 and Fig. 3 show these results.

Table 2 Iterative Solution for Bicycle Rental in a Specific Region

\begin{tabular}{cccccc}
\hline residence & work place & campus & park & business center & subway/bus station \\
\hline 0.1583 & 0.1117 & 0.155 & 0.11 & 0.17 & 0.295 \\
\hline 0.1601 & 0.1412 & 0.1665 & 0.1172 & 0.1665 & 0.2485 \\
\hline 0.1590 & 0.1298 & 0.1620 & 0.1141 & 0.1676 & 0.2675 \\
\hline 0.1594 & 0.1342 & 0.1639 & 0.1153 & 0.1672 & 0.26 \\
\hline 0.1593 & 0.1324 & 0.1631 & 0.1149 & 0.1674 & 0.2629 \\
\hline 0.1594 & 0.1332 & 0.1634 & 0.1150 & 0.1673 & 0.2617 \\
\hline 0.1593 & 0.1330 & 0.1633 & 0.1149 & 0.1673 & 0.2622 \\
\hline 0.1593 & 0.1330 & 0.1634 & 0.1149 & 0.1673 & 0.2621 \\
\hline
\end{tabular}

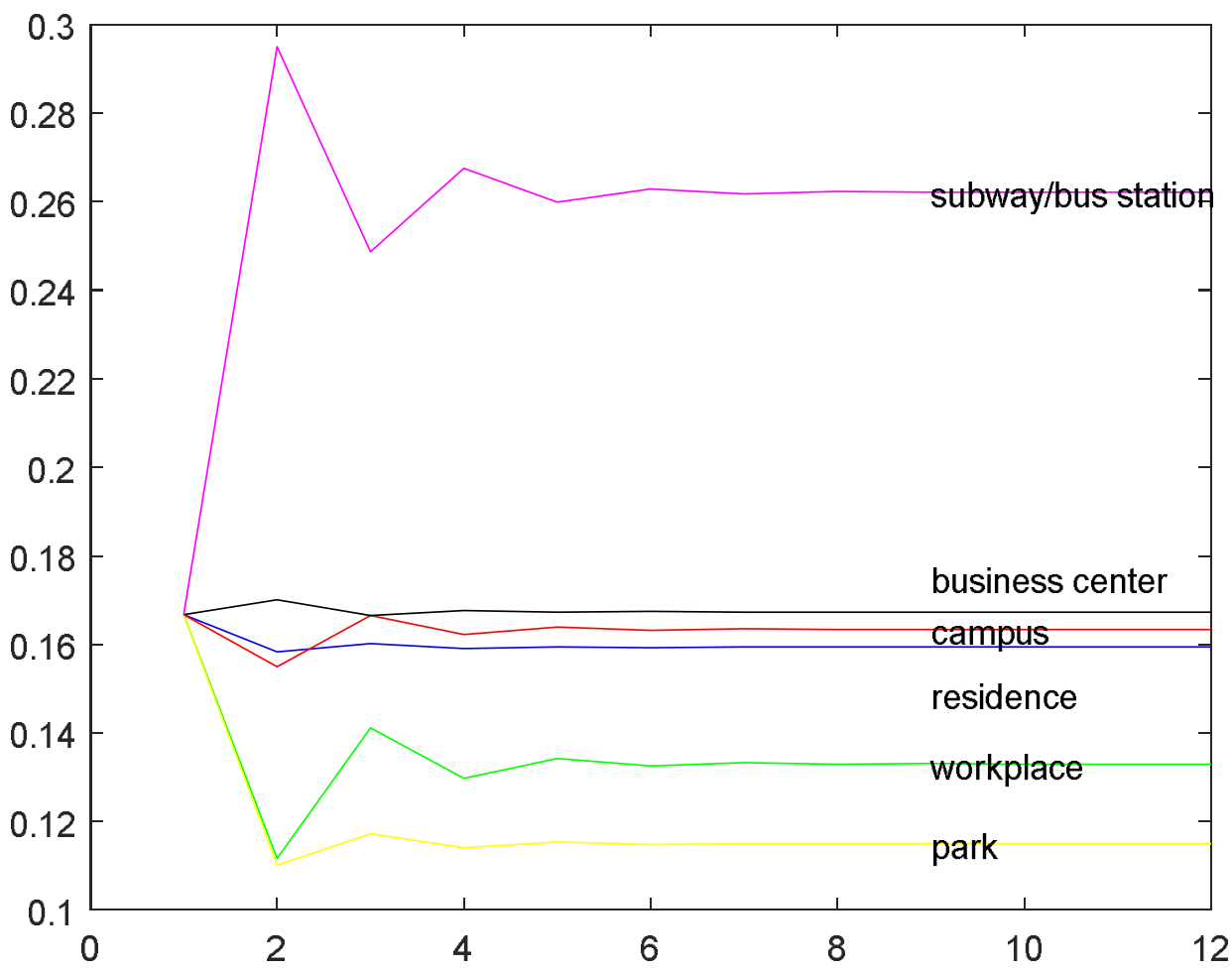

Fig.3 Bicycle Rental Solution in Specific Areas

From the above results, it can be seen that if the number of deliver bicycles in residence, work place, campus, park, commercial center, subway/bus station is total $n$, then about $15.93 \%$ of bicycles will 
be near the residence, $13.3 \%$ will be near the work place, $16.34 \%$ will be on campus, $11.49 \%$ will be in park, $16.73 \%$ will be in commercial center, and $26.21 \%$ will be at subway/bus station after 8 periods. So, at the beginning, if residences, workplaces, campuses, parks, commercial centers, and subway/bus stations each have 2,000 bicycles, then in steady state, there will be 1911 vehicles, 1596 vehicles, 1961 vehicles, 1379 vehicles, 2008 vehicles, and 3145 bicycles in residence, company, campus, commercial center, and subway/bus station respectively. In other words, there will be a balanced between demand and supply of sharing bicycles near residential areas, workplaces, campuses, parks, commercial centers, and subway/bus stations after 8 periods.

Of course, as for the situation of sharing bicycles deliver outside the above six specific areas, regression analysis based on data on profitability and planning and design of all public bicycle systems in the United States, it can be found that the number of stations distributed per square kilometer exceeds 10, and the average station spacing cannot exceed 380 meter.

\section{Conclusions}

In order to better promote the sustainable development between sharing bicycles and urban transportation, this paper studies the issue of sharing bicycles delivery. Through the establishment of the bicycle market demand model that takes into account the age distribution and the specific area model of sharing bicycles, to calculate the amount of sharing bicycles delivery, and guarantees the scientific and rational sharing bicycles delivery in a city or region, makes the supply and demand reach a stable state. In addition, the factors considered in the model and the collected data are not comprehensive enough, and the model needs further improvement.

\section{Acknowledgements}

This work was financially supported by Jiangxi Provincial Postgraduate Innovation Special Fund Project (provincial project, YC2017-S334)

\section{References}

[1] Sharing Cycles and Sustainable Urban Development - The First Symposium on China Urban Transport Development Forum 2017[J/OL]. Urban Transport of China, 2017,(03):1-8. (2017-06-02)[2017-08-07].

[2] C.G. Hou. Analysis Report on China's Sharing Bicycles Market in 2016[J].China Internet, 2017,(02):35-37.

[3] I Research: China Sharing Bicycle Research Report in 2017[R]:

http://report.iresearch.cn/wx/report.aspx?id=2961

[4]BD Research: China Sharing Bicycle Research Report in 2016[R]:

http://www.bigdata-research.cn/content/201702/383.html 